\title{
Microcomputed Tomography Analysis of Mesiobuccal Orifices and Major Apical Foramen in First Maxillary Molars
}

\author{
Gianrico Spagnuolo $^{1, *, \#}$, Gianluca Ametrano, ${ }^{1, \#}$, Vincenzo D’Antò ${ }^{1}$, Anna Formisano ${ }^{1}$, Michele \\ Simeone $^{1}$, Francesco Riccitiello ${ }^{1}$, Massimo Amato ${ }^{2}$ and Sandro Rengo ${ }^{1}$ \\ ${ }^{I}$ Department of Oral and Maxillofacial Sciences, University of Naples “Federico II," Napoli, Italy \\ ${ }^{2}$ Medical School, University of Salerno, Salerno, Italy
}

\begin{abstract}
Objective: Aim of the study was to determined by microcomputed tomography ( $\mu \mathrm{CT}$ ) the horizontal distance between the main (MB1) and the second mesiobuccal canal (MB2) orifices, the vertical distance between the MB1 and MB2 orifices planes, and the distance between the anatomic apex and major apical foramen (AF). Furthermore, we characterized the entire internal and external anatomy of the MB, distalbuccal (DB) and palatal (P) maxillary first molars roots.
\end{abstract}

Materials and Methods: Twenty-two intact extracted first maxillary molars were scanned by X-ray computed transaxial $\mu \mathrm{CT}$ and then 2D and 3D images were processed and analyzed.

Results: The results showed that $77.27 \%$ of the mesiobuccal (MB) roots presented a second MB canal, and $29.41 \%$ of the MB2 were independent from the MB1 canals. In 15 teeth, there were three root canal orifices on the chamber floor, and 10 of these teeth presented MB2 canals. The mean vertical distance between the MB1 and MB2 planes was $1.68 \pm 0.83$ $\mathrm{mm}$. Seven teeth had four orifices. The mean horizontal interorificial distance between the MB1 and MB2 orifices was $1.21 \pm 0.5 \mathrm{~mm}$. Accessory canals were observed in $33.33 \%$ of the roots, loops in $6.06 \%$, while isthmuses were found in 15 of the $22 \mathrm{MB}$ roots. Of the total roots, $74.24 \%$ presented one foramen, while all of the roots showed a major apical foramen that was not coincident with the anatomic apex.

Conclusions: Our $\mu \mathrm{CT}$ analysis provided interesting features on the horizontal and vertical distance between the MB1 and MB2 orifices and on the distance of AF and anatomic apex.

Clinical Relevance: These results have an important clinical value because might support the endodontist in the recruitment, negotiation and obturation of maxillary first molar canal system.

Keywords: First maxillary molar, anatomy, MB2, $\mu \mathrm{CT}$.

\section{INTRODUCTION}

Anatomical variations present in the root canal system might contribute to endodontic treatment failures. Thus, the most successful treatment is often related to a good knowledge of root anatomy $[1,2]$.

Recently, several studies assessed the characteristics of different types of teeth, and researchers focused particular attention on the maxillary first molars because of their complicated root canal morphology [3-7]. The most frequent maxillary first molar pattern reported in the literature showed three roots with a prevalence of four canals because of the presence of two root canals in the mesiobuccal (MB) root [7]. Researchers used in vitro studies to learn about root canal anatomy by using various techniques. The results reported different outcomes in terms of the number of canals, ramifications, localization, number of foramina, and

*Address correspondence to this author at the Department of Oral and Maxillofacial Sciences, University of Naples 'Federico II', Napoli, Italy;

Tel/Fax: +390817462080; E-mail: gspagnuo@unina.it

\#The first two authors equally contributed to the work presence of apical deltas. These differences might depend on the various laboratory methods and techniques used [8].

The development of microcomputed tomography $(\mu \mathrm{CT})$ has gained increasing significance in the study of hard and dental tissues [9]. $\mu \mathrm{CT}$ is a noninvasive method, so the samples can remain intact, whilst an enormous amount of information can be obtained. Slices can be recreated in any plane from the scans, and data can be represented as 2-dimensional (2D) or rendered as 3-dimensional (3D) images. $\mu \mathrm{CT}$ has facilitated studying the internal and external anatomy of teeth, which can be demonstrated simultaneously or separately and be assessed qualitatively and quantitatively $[10,11]$.

Recently, authors have used $\mu \mathrm{CT}$ to study the complex anatomy of upper first molars in order to recognize and locate the mesiobuccal canals (MB1 and MB2). In particular, these studies investigated the morphology of the mesiobuccal root, the curvature, the incidence of MB2 canals, and the presence of isthmuses, accessory canals, apical delta, and loops [12-16]. Nevertheless, to date no researches evaluated by $\mu \mathrm{CT}$ the location of the MB1 and MB2 orificies and the 


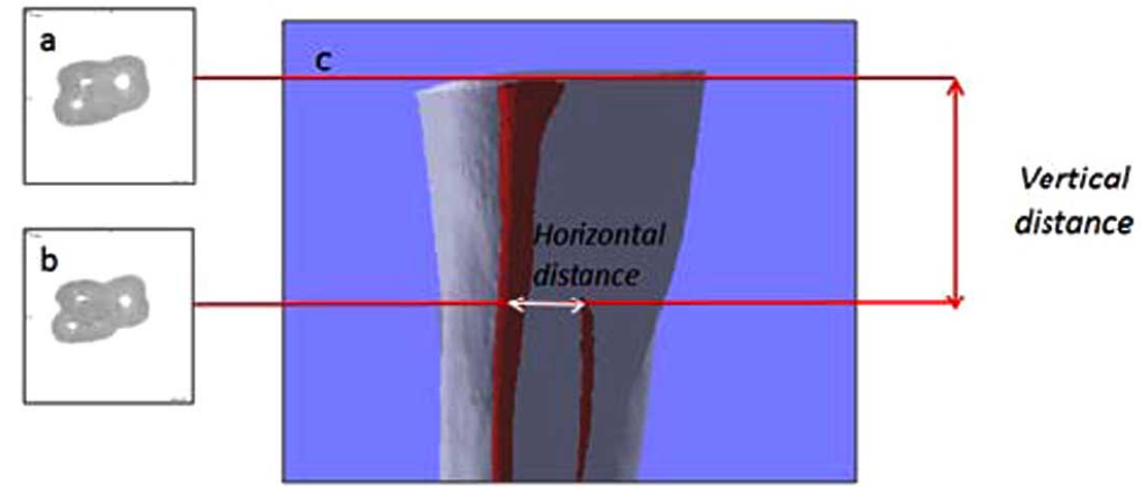

Fig. (1). Representative 3D image of an MB root and 2D images of canal orifices. Three canal orifices at the pulp chamber floor (a) turn into four canals apically in the root (b). Anatomic distances (c) were measured as reported in the materials and methods section.

position of anatomic apex (apical root vertex) related to major apical foramen in first maxillary molars roots.

Therefore, the aim of our study was to noninvasively apply $\mu \mathrm{CT}$ to determine the horizontal distance between the MB1 and MB2 canal orifices (interorificial distance), the vertical distance between the MB1 and MB2 orifices planes, and the distance between the anatomic apex (apical root vertex) and major apical foramen. Moreover we characterized the entire internal and external anatomy of the MB, distalbuccal (DB) and palatal (P) maxillary first molar roots.

\section{MATERIALS AND METHODS}

\section{Samples Selection and Preparation}

A total of 22 intact first maxillary molars were extracted from patients (age 30-50 years), who provided proper informed consent, and were then analyzed. The protocol was reviewed and approved by the Institutional Review Board (University of Naples "Federico II"). Each tooth selected had fully formed apices, intact crowns, no restorations, and no defects or carious lesions. After extraction, the external surfaces of the teeth were carefully cleaned of calculus and soft tissue attachments with an ultrasonic scaler and sodium hypochlorite $(5.25 \%)$. Then, each tooth was stored in a labeled individual plastic vial containing $0.1 \%$ thymol solution until use.

\section{Microcomputed Tomography}

Each tooth was scanned by a fan-beam X-ray sources using $\mu$ CT (SkyScan 1072, SkyScanb.v.b.a., Aartselaar, Belgium). The scanning procedure was completed using the following settings: $10 \mathrm{~W}, 100 \mathrm{kV}, 98 \mu \mathrm{A}$, a $1 \mathrm{~mm}$ thick aluminum plate, and $\times 15$ magnification, with a $5.9 \mathrm{~s}$ exposure time and $0.90^{\circ}$ rotation step. The acquisition procedures consisted of the realization of several 2D lateral projections of the specimens during a $180^{\circ}$ rotation around the vertical axis. The measurement was repeated at each 50,60, 65, 70, and 80 grayscale index of the lower grey threshold level for determination of the optimal threshold level. The automatically set threshold level in analyzing program was 65 . The set of images was then processed through a modified Feldkamp cone-beam reconstruction algorithm provided by Skyscan to get the $2 \mathrm{D}$ reconstruction of the teeth. The digital data were elaborated using reconstruction software (NRecon V1.4.0; SkyScan), which provided new axial cross-sections with a pixel size of $19.1 \times 19.1 \mu \mathrm{m}$. The distance between each cross-section was $38.0 \mu \mathrm{m}$.

\section{Three-Dimensional (3D) Reconstruction}

3D image of an axial portion of the sample was obtained after binarisation of the 2D images by assembling the set of reconstructed cross-sections. After cone beam reconstruction, the raw data were converted to 16-bit grayscale picture files with a resolution of $1024 \times 1024$ pixels. Images were acquired from 502 slices of each tooth. The cross-sectional images were imported into a 3D visualization software package (Mimics software; Materialize, Leuven, Belgium). The $3 \mathrm{D}$ reconstruction permitted examination of the external surface of the root and the internal root canal. To appreciate the internal anatomy, the tooth image was rendered transparent.

\section{Observations on root Anatomy}

The $2 \mathrm{D}$ and $3 \mathrm{D}$ images generated by $\mu \mathrm{CT}$ were processed and analyzed by a single experienced endodontist in order to evaluate the following:

- Prevalence of different root canals types, according to Weine et al. [21] and Vertucci [2].

- Vertical distance between the chamber floor 2D slide and the slide on which MB2 was present (Fig. 1), and the horizontal inter- orifice distance between the MB1 and MB2. The chamber floor was arbitrarily designated as the first 2D slide on which at least three orifices were present. The horizontal interorificial distance was calculated between the center of the MB1 and MB2 orifices on the pulp chamber floor (when MB2 was present), or more apically on the $2 \mathrm{D}$ slide when the MB2 orifice was discernible.

- Number of apical foramina, defined as "the circumference or rounded edge, like a funnel or crater, that differentiates the termination of the cemental canal from the exterior surface of the root" [17].

- Prevalence of apical deltas, defined as "a complex ramification of branches of the pulp canal located near the anatomical apex with a main canal not being discernible"[17].

- Distance between anatomic apex (apical root vertex) and major apical foramen, defined as the region where the canal leaves the root surface next to the periodon- 


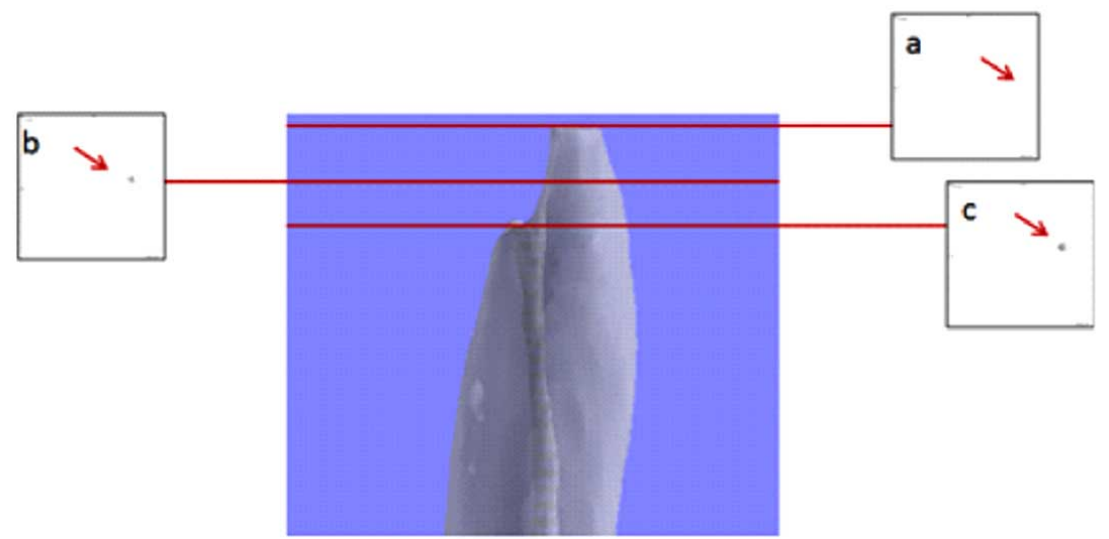

Fig. (2). Representative 2Dand 3D images of an apical third. Anatomic apex (a), major apical foramen (b-c).

Table 1a. Prevalence (\%) of Different Types of Canals, Classified According to Weine et al. (1969)(n=83). The Number of Canals in Each Category is given in Parenthesis

\begin{tabular}{|c|c|}
\hline Type I & $50.57(44)$ \\
\hline Type II & $9.63(8)$ \\
\hline Type III & $12.04(10)$ \\
\hline Type IV & $3(3.61)$ \\
\hline Unclassificable & $21.68(18)$ \\
\hline
\end{tabular}

tal ligament [18]. In order to measure this distance, we selected the $2 \mathrm{D}$ mCT image in the middle of the first and last 2D images of the foramen as the major apical foramen (Fig. 2). When an apical delta or more than three apical foramina were present, we designated the biggest as the major apical foramen.

- Prevalence of accessory canals, defined as "any branch of the main pulp canal or chamber that communicated with the external surface of the root" [17].

- Prevalence of loops, defined as "a branch of the main canal that divides from it and then rejoins in the original canal" [17].

- Prevalence of isthmuses, defined as "a narrow, ribbon shaped communication between two root canals that contains pulp tissue" [19]. Their locations were noted, and the isthmuses were classified according to Fan et al. [20] as the following: Type I, sheet connection; Type II, separate; Type III, mixed; and Type IV, cannular connection.

\section{RESULTS}

\section{Root Canal Configurations}

All teeth analyzed presented three roots. There were 17 teeth $(77.27 \%)$ with four canals, and the remaining teeth $(n=5)$ had three canals. The DB, MB, and P root canal configurations were examined and classified by Weine et al. [21] and Vertucci's [2] methods, and the data are summarized in Tables $\mathbf{1}$ and $\mathbf{2}$.

Analysis of data revealed that only $78 \%$ of canals could be classified according to Weine et al. [21]. Table 1 revealed
Table 1b. Prevalence (\%) of Different Types of Canals, Classified According to Vertucci $(1984)(n=83)$. The Number of Canals in each Category is given in Parenthesis

\begin{tabular}{|c|c|}
\hline Type I & $50.57(44)$ \\
\hline Type II & $9.63(8)$ \\
\hline Type III & $2.4(2)$ \\
\hline Type IV & $12.04(10)$ \\
\hline Type V & $3.61(3)$ \\
\hline Type VI & $7.22(6)$ \\
\hline Type VII & $2.4(2)$ \\
\hline Type VIII & - \\
\hline Unclassificable & $9.63(8)$ \\
\hline
\end{tabular}

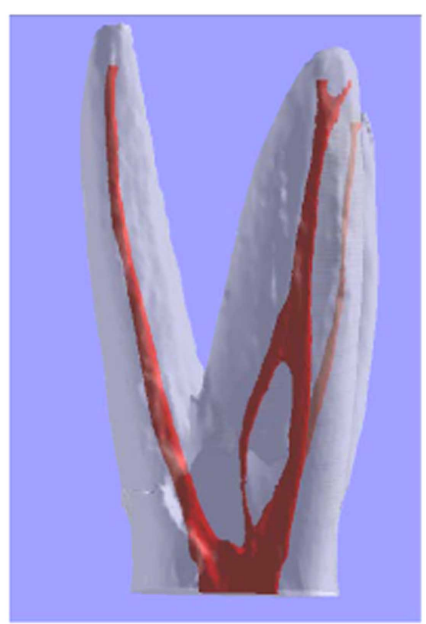

Fig. (3). Representative image of a Type VI canal, classified according to Vertucci (1984).

that Type I root canals were more prevalent. The unclassifiable canals ended with a delta or three foramina $(8 / 87)$ or showed anatomical variations (10/87), but they were classifiable according to Vertucci [2] (Fig. 3). When the root canals were classified according to Vertucci [2] (Table 1b), it was possible to classify almost $90 \%$ of them. The remaining $10 \%$ were not classified because they ended with a delta or three different foramina. The results demonstrate that $77.27 \%$ of MB roots presented MB2 canals, and $29.41 \%$ of MB2 were 
Table 2a. Prevalence (\%) of Different Types of MB, DB, and Pcanals, Classified According to Weine et al. (1969). The Number of Roots in Each Category is Given in Parenthesis

\begin{tabular}{|c|c|c|c|c|}
\hline & \multicolumn{2}{|c|}{ Mesiobuccal Root } & Distobuccal Root & Palatal Root \\
\hline & MB1canals & MB2 canals & & $90.90(20)$ \\
\hline \hline Type I & $13.63(3)$ & - & - & - \\
\hline Type II & $18.18(4)$ & $23.53(4)$ & - & - \\
\hline Type III & $22.72(5)$ & $29.41(5)$ & - & $4.54(1)$ \\
\hline Type IV & $9.09(2)$ & - & $4.54(1)$ & $4.54(1)$ \\
\hline Unclassificable & $36.36(8)$ & $47.05(8)$ & 22 & 22 \\
\hline Tot. & 22 & 17 & & \\
\hline
\end{tabular}

Table 2b. Prevalence (\%) of Different Types of MB, DB,and Pcanals, Classified According to Vertucci (1984). The Number of Roots in each Category is given in Parenthesis

\begin{tabular}{|c|c|c|c|c|}
\hline & \multicolumn{2}{|c|}{ Mesiobuccal Root } & Distobuccal Root & Palatal Root \\
\hline & MB1 canals & MB2 canals & & \\
\hline \hline Type I & $13.63(3)$ & & $95.65(21)$ & - \\
\hline Type II & $18.18(4)$ & $23.53(4)$ & - & - \\
\hline Type III & $4.54(1)$ & $5.88(1)$ & - & - \\
\hline Type IV & $22.72(5)$ & $29.41(5)$ & - & $4.54(1)$ \\
\hline Type V & $9.09(2)$ & & - & - \\
\hline Type VI & $13.6(33)$ & $17.64(3)$ & - & - \\
\hline Type VII & $4.54(1)$ & $5.88(1)$ & - & - \\
\hline Type VIII & - & - & $4.54(1)$ & $4.54(1)$ \\
\hline Unclassificable & $13.63(3)$ & $17.64(3)$ & 22 & 22 \\
\hline Tot. & 22 & 17 & & \\
\hline
\end{tabular}

independent from MB1 canals. Tables 2 reports the detailed data by root type. According to Weine et al.'s classification [21], there were $63.64 \%$ of MB1 and $52.95 \%$ of MB2 canals (Table 2a), and the most common MB1 and MB2 morphology was Type III. In contrast, the analysis of MB1 and MB2 canals by Vertucci's method [2] showed that there were $86.37 \%$ of $\mathrm{MB} 1$ and $82.36 \%$ of MB2 canals (Table $\mathbf{2 b}$ ). Moreover, the majority of the DB and $\mathrm{P}$ roots $(95.45 \%$ and $90.90 \%$, respectively) presented the Type I configuration according to both methods.

\section{Distances Between MB1 and MB2 Canal Orifices}

Five teeth showed three orifices and no MB2 canals. In contrast, in another 10 teeth, MB2 canals were present, but they were not evident on the first 2D slide considered as the pulp chamber floor (Fig. 1a). In these cases, the average vertical distance between the MB1 plane at the chamber floor and the MB2 orifice canal (Fig. 1b) plane was $1.68 \pm 0.83$ $\mathrm{mm}$ (Fig. 1). The remaining seven teeth analyzed showed four orifices on the pulp chamber floor. The mean 1 horizontal distance between the orifices was $1.21 \pm 0.5 \mathrm{~mm}$ (Fig. 1).

\section{Apical Foramina and Presence of Apical Delta}

One foramen was observed in $74.24 \%(n=49)$ of the total roots (DB, $\mathrm{MB}$ and $\mathrm{P})$, while two foramina were present in $18.18 \%(n=12)$ of the roots, particularly in MB roots $(11 / 12)$.
Three roots ended with an apical delta, while two roots ended with three main foramina (diameters larger than 10 nm) (Table 5) (Fig. 4).

\section{Distance Between Anatomic Apex (Apical Root Vertex) and Major Apical Foramen}

All of the analyzed roots showed a major apical foramen that was not coincident with the anatomic apex (Fig. 2). The localization of the apical foramen varied considerably, tending to lie on the palatal and distal aspect of the roots. The $\mathrm{P}$ roots $(n=22)$ showed a mean distance value of $0.488 \pm 0.224$ $\mathrm{mm}$ between the apical foramen and anatomic apex. The DB roots $(n=22)$ had a mean distance of $0.371 \pm 0.182 \mathrm{~mm}$. The $\mathrm{MB}$ roots $(\mathrm{n}=22)$ had higher values compared to the other
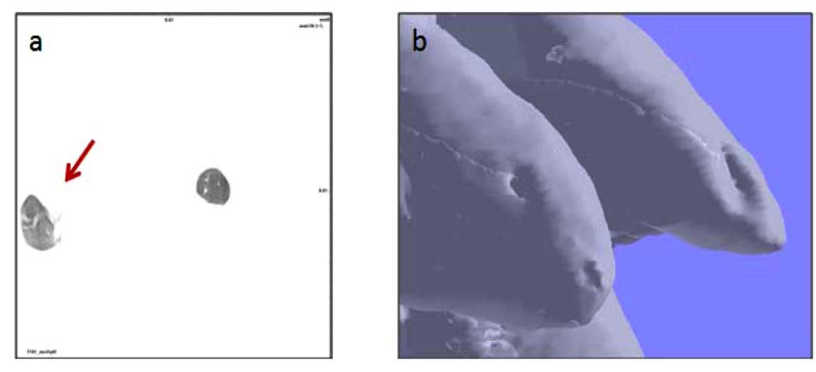

Fig. (4). Representative images of an apical delta. 2D image (a) and 3D image (b). 
Table 3. Prevalence (\%) of Accessory Canals and Loops. The Number of roots in each Category is given in Parenthesis

\begin{tabular}{|c|c|c|c|c|}
\hline & & MB Root & DV Root & P Root \\
\hline \hline Accessory canals & & $68.18(15)$ & $9.09(2)$ & $40.9(9)$ \\
\hline Loops & & $9.09(2)$ & $9.09(2)$ & - \\
\hline
\end{tabular}

Table 4. Prevalence (\%) of Isthmuses. The Number of Isthmuses Present in each Category is given in Parenthesis

\begin{tabular}{|c|c|c|c|}
\hline & Coronal Third & Middle Third & Apical Third \\
\hline \hline Isthmuses & $36(9)$ & $48(12)$ & $16(24)$ \\
\hline \hline
\end{tabular}

Table 5. Number of Apical Foramina

\begin{tabular}{|c|c|c|c|c|}
\hline & One Foramen & Two Foramina & Three Foramina & Apical Delta \\
\hline \hline MB roots & 8 & 11 & 2 & 1 \\
\hline DB roots & 21 & - & - & 1 \\
\hline P roots & 20 & 1 & 2 & 3 \\
\hline Tot. & 49 & 12 & - & 1 \\
\hline
\end{tabular}
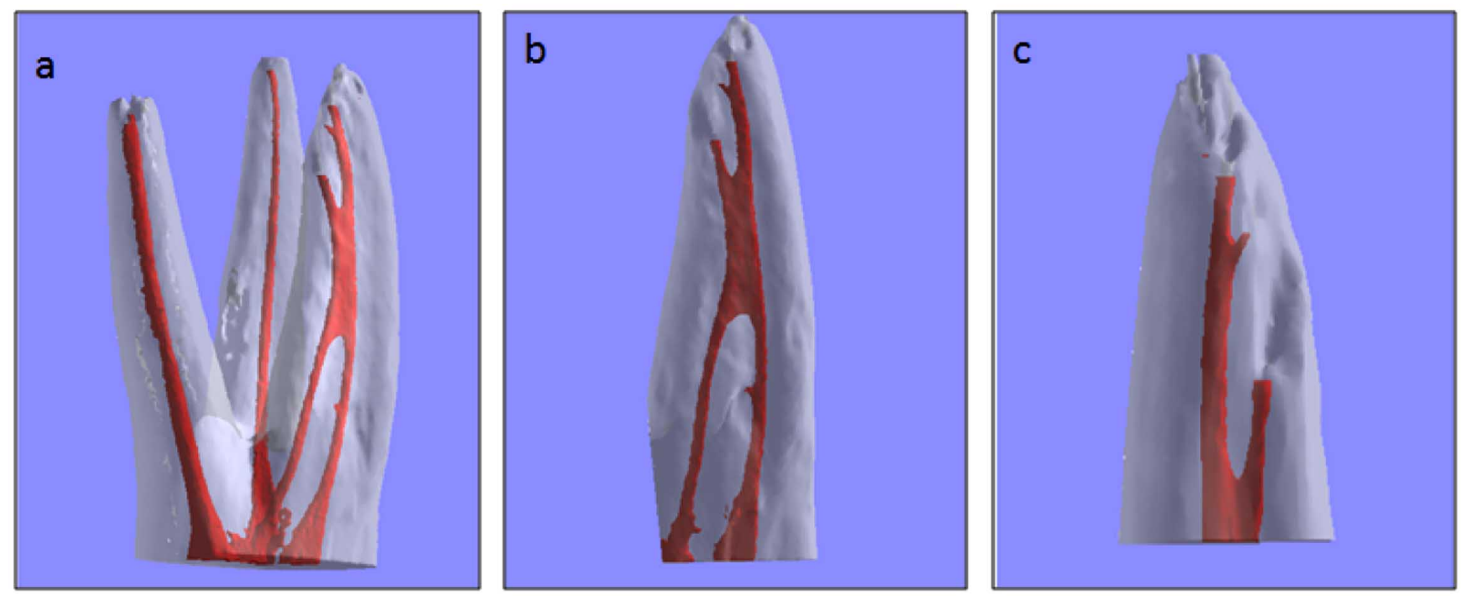

Fig. (5). Representative image of a lateral canal in a MB root (a). Particular of root (b). Magnification (c).

roots. In particular, when the MB roots had one canal, the distance between the apical foramen and anatomic apex was $0.712 \pm 0.543 \mathrm{~mm}$, while the MB2 canal had a main distance of $1.416 \pm 0.650 \mathrm{~mm}$.

\section{Accessory Canals, Loops, and Isthmuses}

The prevalence of accessory canals, loops, isthmuses is reported in Tables 3 and 4. Accessory canals were present in $39.39 \%$ of the roots $(n=26)$, and all of them were located in the apical third (Fig. 5). They were mainly found in the MB roots $(11 / 22$ roots) and $\mathrm{P}$ roots $(9 / 22)$. Moreover, loops were observed in $6.06 \%(\mathrm{n}=4)$ of specimens. In particular, loops were observed in $\mathrm{MB}$ (in the coronal and apical third) $(n=2)$ and in DB roots (in the middle third) $(n=2)$ (Fig. 6). Isthmuses $(n=25)$ were found in $15 \mathrm{MB}$ roots, and $6 \mathrm{MB}$ roots had multiple isthmuses (40\%). The majority of the isthmuses were localized in the middle third $(12 / 25)$. The isthmuses were classified according to Fan et al.(2010). There were more Type I isthmuses (15/25)than the others types. The data showed that Type II (3/25) and Type IV (7/25) isthmuses were also present.

\section{DISCUSSION}

With a good knowledge of tooth anatomy, endodontists can implement the correct procedure for cleaning and shaping the root canal system and reduce treatment failure rates.

Doubtlessly, failure to locate and treat the second mesiobuccal canal in the maxillary first molar might change the long-term treatment prognosis [21, 22]. In order to facilitate treatment, several reports evaluated MB2 canal anatomy using various techniques [7, 8, 12, 14-17, 22, 23-25]. Traditional in vitro methods for studying root canal anatomy are generally destructive and produce irreversible changes to the specimen. In contrast, the $\mu \mathrm{CT}$ system is a non invasive, non destructive approach that allows for precise evaluation of root canal anatomy. 3D reconstruction can be used to put together different parts of a tooth. By making the dental hard tissues transparent and the pulp chamber and root canal system opaque, both the external and internal morphology of a tooth can be conveniently reconstructed. Here, the main propose was to study the location of MB canal orifices and the position of anatomic apex (apical root vertex) and major 

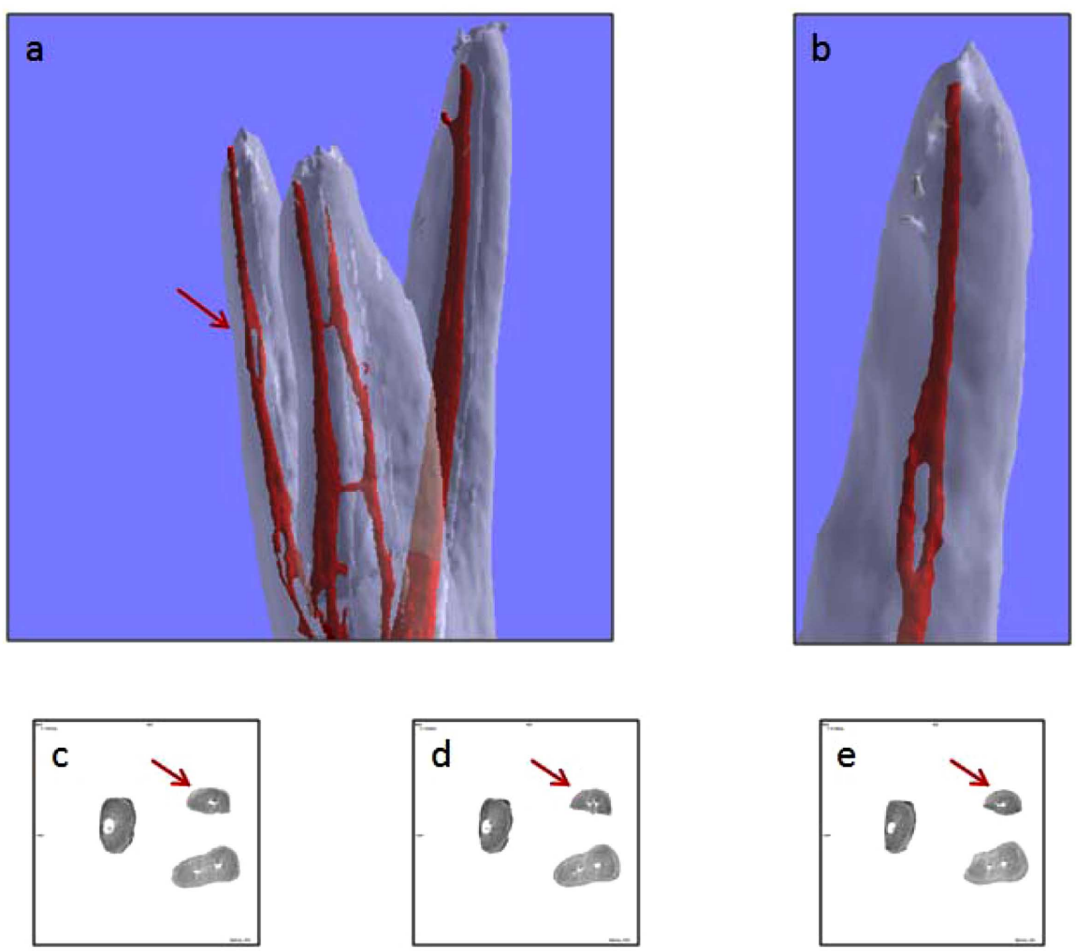

Fig. (6). Representative images of a loop in a DV root. 3D images (a) and magnification (b). 2D images, before the loop (c), of the loop (d), and after the loop (e).

apical foramen in first maxillary molars roots by using $\mu \mathrm{CT}$. Furthermore, we characterized the root canals pathway and anatomy.

As previously reported [6, 17], we located the MB2 canal close to the MB canal in the buccolingual direction, slightly mesial to a line joining the MB and palatine canals. So far studies focused on the horizontal distance between the MB1 and MB2 canals at the orifice level and further apically in the root by using different in vitro techniques including scanning electron microscopy (SEM) and operative microscopy [3, 25, 26], but no studies used $\mu \mathrm{CT}$. Our $\mu \mathrm{CT}$ results showed that seven teeth had four orifices on the chamber floor, whereas in 10 teeth, the MB2 canals were not visible on the chamber floor plane. Therefore, $77.27 \%$ of teeth presented four orifices. Interestingly, the vertical mean distance between the two planes passing through the MB1 and MB2 orifices was $1.68 \pm 0.83 \mathrm{~mm}$, whereas the mean horizontal distance (interorificial distance) was $1.21 \pm 0.5 \mathrm{~mm}$. Our data were in agreement with previous studies performed using different techniques. Gilles et al. [25] showed the presence of four orifices in $81 \%$ of the first molars analyzed by SEM, and the mean distance between the MB1 and MB2 orifices was approximately $2.31 \mathrm{~mm}$. Other studies [3, 26] used DOM to evaluate the location of the MB2 canal and the distance between the MB orifices in the maxillary first molars. They reported an interorificial horizontal distance similar to our data. Moreover, Kulild and Peters observed a comparable mean distance of $1.82 \mathrm{~mm}$ between the MB1 and MB2 orifices. Differently from the latter studies, our $\mu \mathrm{CT}$ analysis provided original and interesting information about the vertical distance between MB2 orifice and pulp chamber floor and these data would be useful for endodontists in clinical practice in the location of MB2 canal orifice not only at chamber level but also apically.
The complex anatomic configuration of the MB root canal system has long been the subject of considerable investigation, but the results of these studies are disparate both in regards to the numbers of canals and their pathways, depending on the methods used. In clinical trials, the percentage of MB2 canals varies from $18.6 \%$ [27] to $80.3 \%$ [28]. Laboratory studies showed a higher prevalence of MB2canals, ranging from $30 \%$ [29] to $96 \%$ [3]. Here, MB2 canals were present in $77.27 \%$ of analyzed MB roots, and $29.41 \%$ of them run completely detached from the respective MB1. These results were in agreement with recent $\mu \mathrm{CT}$ studies, which analyzed a similar number of first molars [15, 16]. Compared to our results, Somma et al. [15] observed a higher percentage of MB2 canals that were completely detached from MB1 (42\% vs. 29.41\%), whereas Verma \& Love found $18 \mathrm{MB}$ roots with two canals, and two roots that showed independent canals [16]. In a study using cone beam computed tomography (CBCT), Blattner et al. [23] reported a lower percentage of MB2 $(57.9 \%)$ than our data and previous $\mu \mathrm{CT}$ analyses $[15,16]$. These differences might be due to the lower resolution of CBCT images compared to $\mu \mathrm{CT}$.

Moreover in our study, we found the presence of single or multiple isthmuses in $63.63 \%$ of $\mathrm{MB}$ roots, and isthmuses were more frequently found in the middle third (48\%), as previously reported $[2,15]$. The majority of isthmuses were classified as Type I, according to Fan et al. [20]. Our data about the highest prevalence of isthmuses in the MB (52\%) were in agreement with Vertucci [2]. Furthermore, our results showed the presence of loops mainly in the apical third of $\mathrm{MB}$ roots, in agreement with the study by Somma et al. [14]. Our analysis also showed a prevalence of accessory canals in MB roots (Table 3), similar to previous studies performed using $\mu \mathrm{CT}[15,16]$. In agreement with these reports, the accessory canals were located in the apical region. 
In addition, we found that $47.05 \%(8 / 17)$ of MB2 canals ended with an independent apex. These data were in line with those of Verma \& Love, which reported a detached MB2 foramen in 7 of $18 \mathrm{MB}$ roots [16].

Recently, a study on maxillary molar roots showed that the apical constriction (AC) was not present in a significant percentage of roots [30], while the major apical foramen (AF) may be a useful landmark for instrumentation and obturation [31]. Hence, in our study, we focused on AF rather than on $\mathrm{AC}$, and we evaluated the distances between $\mathrm{AF}$ and the apical vertex. It has been shown that the AF coincides with the anatomical apex in $17-46 \%$ of cases [32-34], whereas when they did not match, the AF had a variable distance. Gutierrez et al. [33] evaluated this distance with SEM and measured a distance ranging from $0.62-3.80 \mathrm{~mm}$ in $\mathrm{MB}$ roots, a distance ranging from $0.23-0.93 \mathrm{~mm}$ in DB roots, and a distance ranging from $0.8-2.12 \mathrm{~mm}$ in $\mathrm{P}$ roots. Our results carried out by $\mu \mathrm{CT}$ analysis were in line with latter studies, confirming a greater apical foramen-anatomical apex distance in MB roots. Moreover, our data provided evidence that apical foramen was deviated and not coincident with apical vertex in all examined roots suggesting that the radiographic images might not accurately identify the "working length" for a successful treatment.

\section{CONCLUSION}

In agreement with previous reports, our study confirms that $\mu \mathrm{CT}$ is a good, suitable, and non invasive method that can be used to evaluate and provide detailed anatomical characteristics of the root canals system. In particular our results present new and original information on the location of MB2 canals orifices and on the position of apical foramen and anatomic apex. Therefore, these additional anatomical features reported in the present study might support endodontic practitioners in the recruitment, negotiation and obturation of maxillary first molar canal system.

\section{CONFLICT OF INTEREST}

The authors declare that they have no conflict of interest.

\section{ACKNOWLEDGEMENT}

None declared.

\section{REFERENCES}

[1] Hess W. The anatomy of the root-canals of the teeth of the permanent dentition, part 1. New York: William Wood and Co 1925.

[2] Vertucci FJ. Root canal anatomy of the human permanent teeth. Oral Surg Oral Med Oral Pathol Oral Radiol Endod 1984; 58: 5899.

[3] Kulild JC, Peters DD. Incidence and configuration of canal systems in the mesiobuccal root of maxillary first and second molars. J Endod 1990; 16: 311-7.

[4] Pecora JD, Woelfel JB, Sousa Neto MD, Issa EP. Morphologic study of the maxillary molars. Part II: internal anatomy. Braz Dent J 1992; 3: 53-7.

[5] Thomas RP, Moule AJ, Bryant R. Root canal morphology of maxillary permanent first molar teeth at various ages. Int Endod J 1993; 26: 257- 67.

[6] Stropko JJ. Canal morphology of maxillary molars: clinical observations of canal configurations. J Endod 1999; 25: 446 -50.

[7] Cleghorn BM, Christie WH, Dong CCS. Root and root canal morphology of the human permanent maxillary first molar: a literature review. J Endod 2006; 32: 813-21.
[8] Baratto FF, Zaitter S, Haragushiku GA, de Campos EA, Abuabara A, Correr GM. Analysis of the internal anatomy of maxillary first molars by using different methods. J Endod 2009; 35: 337-42.

[9] Rhodes JS, Ford TR, Lynch JA, Liepins PJ, Curtis RV. Microcomputed tomography: a new tool for experimental endodontology. Int Endod J 1999; 32: 165-70.

[10] Bjorndal L, Carlsen O, Thuesen G, Darvann T, Kreiborg S. External and internal macromorphology in 3D-reconstructedmaxillary molars using computerized x-ray microtomography. Int Endod J 1999; 32: 3-9.

[11] Plotino G, Grande NM, Pecci R, Bedini R, Pameijer CH, Somma F. Three-dimensional imaging using microcomputed tomography for studying the external and internal macromorphology of teeth. J Am Dent Assoc 2006; 137: 1555-61.

[12] Eder A, Kantor M, Nell A, et al. Root canal system in the mesiobuccal root of the maxillary first molar: an in vitro comparison study of computed tomography and histology. Dentomaxillofac Radiol 2006; 35: 175-7.

[13] Lee JK, Ha BH, Choi JH, Heo SM, Perinpanayagam H. Quantitative three-dimensional analysis of root canal curvature in maxillary first molars using micro-computed tomography. J Endod 2006; 32: 941-5.

[14] Park JW, Lee JK, Choi JH, Perinpanayagam H. Three-dimensional analysis of maxillary first molar mesiobuccal root canal configuration and curvature using micro-computed tomography. Oral Surg Oral Med Oral Pathol Oral Radiol Endod 2009; 108: 437-42.

[15] Somma F, Leoni D, Plotino G, Grande NM, Plasschaert A. Root canal morphology of the mesiobuccal root of maxillary first molars: a micro-computed tomographic analysis. Int Endod J 2009; 42: $165-74$

[16] Verma P, Love RM. A micro CT study of the mesiobuccal root canal morphology of the maxillary first molar tooth. Int Endod $\mathrm{J}$ 2011; 44: 210-7.

[17] Vertucci FJ. Root canal morphology and its relationship to endodontic procedures. Endodontic Top 2005; 10: 3-29.

[18] American Association of Endodontists. An annotated glossary of terms used in endodontics. Chicago, IL: American Association of Endodontists 1984; pp. 1-3.

[19] Weller NR, Niemczyk SP, Kim S. Incidence and position of the canal isthmus. Part 1. Mesiobuccal root of the maxillary first molar. J Endod 1995; 21: 380-3.

[20] Fan B, Pan Y, Gao Y, Fang F, Wu Q, Gutmann JL. Threedimensional morphologic analysis of isthmuses in the mesial roots of mandibular molars. J Endod 2010; 36: 1866-9.

[21] Weine FS, Healey HJ, Gerstein H, Evanson L. Canal configuration in the mesiobuccal root of the maxillary first molar and its endodontic significance. Oral Surg Oral Med Oral Pathol Oral Radiol Endod 1969; 28: 419 -25.

[22] Wolcott J, Ishley D, Kennedy W, Johnson S, Minnich S. Clinical investigation of secondmesiobuccal canals in endodontically treated and retreated maxillary molars. J Endod 2002; 28: 477-9.

[23] Blattner TC, George N, Lee CC, Kumar V, Yelton CDJ. Efficacy of cone-beam computed tomography as a modality to accurately identify the presence of second mesiobuccal canals in maxillary first and second molars: a pilot study. J Endod 2010; 36: 867-70.

[24] Bauman R, Scarfe W, Clark S, Morelli J, Scheetz J, Farman A. Ex vivo detection of mesiobuccal canals in maxillary molars using CBCT at four different isotropic voxel dimensions. Int Endod J 2011; 44: 752-8.

[25] Gilles J, Reader A. A SEM investigation of the mesiolingual canal in human maxillary first and second molars. Oral Surg Oral Med Oral Pathol Oral Radiol Endod 1990; 70: 638-43.

[26] Gorduysus MO, Gorduysus M, Friedman S. Operating microscope improves negotiation of second mesiobuccal canals in maxillary molars. J Endod 2001; 27: 683-6.

[27] Hartwell G, Bellizzi R. Clinical investigation of in vivo endodontically treated mandibular and maxillary molars. J Endod 1982; 8: 555-7.

[28] Neaverth EJ, Kotler LM, Kaltenbach RF. Clinical investigation (in vivo) of endodontically treated maxillary first molars. J Endod 1987; 13: 506-12.

[29] Sykaras S, Economou P. Root canal morphology of the mesiobuccal root of the maxillary first molar. Oral Res Abs 1971; 2025.

[30] Meder-CL, Williamson AE, William T. Johnson WT, Vasilescu D, Richard WR. Apical morphology of the palatal roots of maxillary 
molars by using micro-computed tomography. J Endod 2011; 37: $1162-5$.

[31] Wu MK, Wesselink PR, Walton RE. Apical terminus location of root canal treatment procedures. Oral Surg Oral Med Oral Pathol Oral Radiol Endod 2000; 89: 99-103.

[32] Kuttler Y. Microscopic investigation of root apexes. J Am Dent Assoc 1955; 50: 544-52.
[33] Gutierrez JH, Aguayo P. Apical foraminal openings in human teeth. Number and location Oral Surg Oral Med Oral Pathol Oral Radiol Endod 1995; 79: 769-77.

[34] Ricucci D, Langeland K. Apical limit of root canal instrumentation and obturation, part 2 a histological study. Int Endod J 1998; 31: 394-409.

Received: April 13, 2012

Revised: May 20, 2012

Accepted: May 21, 2012

(C) Spagnuolo et al.; Licensee Bentham Open.

This is an open access article licensed under the terms of the Creative Commons Attribution Non-Commercial License (http://creativecommons.org/licenses/by$\mathrm{nc} / 3.0 /$ ) which permits unrestricted, non-commercial use, distribution and reproduction in any medium, provided the work is properly cited. 